\title{
Titulares da agenda e carreiras políticas
}

\author{
Agenda holders and political careers
}

Como enfatizam vários autores, a produção legal no Brasil é, em grande parte, controlada pelo Poder Executivo. Verifica-se que cerca de $80 \%$ das leis sancionadas têm suas proposições iniciais oriundas desse poder (Figueiredo e Limongi, 2001, p. 50-51). Essas informações sobre o processo legislativo, objeto de citação em vários outros trabalhos (Pereira e Mueller, 2000, p. 65; Amorim Neto e Santos, 2003, p. 664; Pereira, Power e Rennó, 2005, p. 403; Amorim Neto, 2006, p. 130), mostram o Executivo como "principal legislador de jure e de fato" (Figueiredo e Limongi, 2001, p. 41).

A preponderância do Executivo sobre o Legislativo tem origens históricas e costuma ser explicada por regras constitucionais que asseguram ao presidente da República a exclusividade na apresentação de projetos de lei relativos à organização da administração federal em senso estrito e ao orçamento, a possibilidade de adoção das medidas provisórias, bem como o poder de solicitar urgência da tramitação de determinadas matérias ${ }^{1}$. Esses instrumentos são reforçados pela capacidade de centralização do processo decisório pelos líderes dos partidos da coalizão majoritária dentro do Congresso. Um conjunto interligado de fatores permite que o presidente da República molde ou até mesmo defina a agenda legislativa. Nessa perspectiva,

É doutoranda no Programa de Pós-Graduação em Ciência Política da Universidade de Brasília (Brasília, DF) e mestre pela mesma instituição. E-mail: suelymvg@gmail.com.

** É doutorando no Programa de Pós-Graduação em Ciência Política da Universidade de Brasília (Brasília, DF) e mestre pela mesma instituição. E-mail: rsilveirasilva@gmail.com.

Ver arts. 61, §10, 62, 64, § 10, e 165 da Constituição Federal. 
muitos autores tendem a colocar em relevo a passividade do parlamento, especialmente no campo da elaboração das leis, em concordância presumida e constatada pelo índice de sucesso das propostas apresentadas pelo Executivo. Essa visão fica evidenciada nas pesquisas sobre as carreiras políticas, cujos resultados colocam a arena legislativa, que aqui trataremos como a arena da produção de leis, como a menos recomendada, estrategicamente falando, no que concerne à sobrevivência eleitoral.

Neste artigo, mostraremos que a arena da produção de leis também pode ser uma via importante para construir e consolidar carreiras políticas, mesmo não sendo o locus preferido pela maioria dos políticos. De forma geral, entende-se que o papel que os parlamentares podem assumir na condução das matérias que tramitam no Congresso Nacional, bem como os efeitos dessa atuação, necessita ser mais explorado no que se refere a carreiras.

Será aqui trabalhada a seguinte questão: quem são os parlamentares que assumem destaque na articulação política na arena da produção de leis, servindo de referência para os grupos organizados, e como essa atuação diferenciada repercute sobre suas carreiras políticas. Utilizaremos um termo cunhado por Silva e Araújo (2010a, 2010b) para designar esses agentes: titulares da agenda (agenda holders).

O parlamentar que assume o papel de titular da agenda não o faz apenas quando é relator. Pode ser o próprio autor que acompanha a tramitação de sua proposição legislativa, participando ativamente das discussões e negociações, e servindo de ponte ao(s) relator(es) ao longo do processo. Também pode ser o parlamentar no exercício de função similar à relatoria, como a coordenação de um grupo de trabalho ou, ainda, o parlamentar especializado que se consolida como negociador em tema determinado.

Nosso entendimento é o de que parlamentares que reúnem experiência na vida política e capacidade de articulação, dentro ou fora do Congresso Nacional, tendem a se estabelecer como titulares da agenda e fortalecer suas carreiras.

Recorreremos aos estudos de caso para realizarmos a análise e, como recorte para a seleção de dados, utilizaremos os processos destacados por Silva e Araújo (2010a, 2010b) no estudo do fenômeno da apropriação da agenda do Legislativo ${ }^{2}$. Por meio de análise dos dados de alguns desses processos

Segundo Silva e Araújo (2010a, 2010b), o fenômeno da apropriação ocorre quando o Executivo lança mão da prática de tomar assuntos e matérias que já estão em discussão no Congresso Nacional para formular projetos de sua própria iniciativa. Em muitos casos, os autores observaram projetos similares ou mesmo 
legislativos, complementados com o rastreamento de informações sobre a carreira política de parlamentares, pretende-se encontrar caminho para responder (i) quem são os titulares da agenda e como eles atuam; e (ii) se essa atuação influencia as carreiras políticas.

\section{Estudos legislativos e carreiras políticas}

É preciso compreender como se encontram as pesquisas sobre carreiras políticas no âmbito dos estudos legislativos brasileiros, para podermos estabelecer o lugar a ser ocupado pela conceituação dos titulares da agenda. Inicialmente, os estudos foram fortemente influenciados por autores como Schlesinger (1966), Mayhew (1974) e Rohde (1979), que introduziram e desenvolveram teorias de construção de carreiras mediante os conceitos de ambição estática, quando um indivíduo pretende permanecer em um mesmo posto por vários mandatos consecutivos, o que corresponderia à reeleição, e de ambição progressiva, situação em que o político candidata-se a um posto "mais alto" do que o que ocupa. Mayhew (1974) observou uma taxa de rotatividade cada vez menor e um número cada vez maior de mandatos consecutivos entre os congressistas norte-americanos desde o século XIX, argumentando que os parlamentares caminhavam à profissionalização e que suas carreiras teriam como objetivo a reeleição, ou seja, uma ambição estática. Posteriormente, Rohde (1979) concluiu que os parlamentares se diferenciam quanto a sua propensão a assumir riscos, ou seja, aqueles com maior propensão a assumir riscos candidatam-se a cargos mais altos, predominando entre os parlamentares a preferência a priori pela ambição progressiva, desde que sua conquista não represente custo ou risco.

Aderindo a essa perspectiva, o debate chegou ao Brasil por meio do trabalho de Samuels (2000), que defendeu o padrão da ambição progressiva no caso brasileiro. Estudando a Câmara dos Deputados, o autor verifica que havia um elevado número de candidaturas para postos fora do Legislativo, preferencialmente postos nos executivos municipais, estaduais, ministérios e secretariado. Além disso, alega que deputados "pesos pesado", aqueles que se projetam mais na Câmara diante da opinião pública, seus partidos e pares, preferiam competir em outras esferas de poder. Consequentemente, restaria aos deputados "pesos leve”, ou seja, os mais vulneráveis, a opção pela reeleição.

idênticos aos dos parlamentares, seja da oposição, seja da base de apoio ao governo. Neste trabalho, determinados casos de apropriação foram usados para a análise da atuação dos titulares da agenda. 
A partir dessas conclusões, iniciou-se uma busca para refinar a questão das carreiras. Ao estudar apenas a decisão pela reeleição dos deputados, Pereira e Rennó $(2001,2007)$ levantam um conjunto de variáveis que indicariam a atividade do parlamentar ${ }^{3}$, reservando especial importância à arena orçamentária, destacando o número de emendas aprovadas e executadas para verificar sua relevância na estratégia da reeleição.

Pereira e Rennó $(2001,2007)$ chamam a atenção para o fato de que o panorama institucional do sistema político brasileiro oferece mais restrições para que o parlamentar possa influenciar e afetar aquilo que o Legislativo produz, reforçando o argumento de que carreiras moldadas nas atividades legislativas são desestimuladas. Para esses autores, a tentativa de capitalizar a atenção ou se promover em função de alguma realização (credit claiming) por meio das emendas orçamentárias é o principal elemento para as escolhas dos políticos e, por isso, sobressai a relevância dos vínculos estabelecidos com o Poder Executivo. Isso indicaria uma desconexão entre a atuação parlamentar na esfera da produção de leis e os resultados eleitorais (Pereira e Rennó, 2001, p. 168).

Variáveis como número de projetos e número de mandatos (seniority) não tiveram significância na explicação. Não obstante, os estudos ressalvam que há parlamentares com estratégia nacional (qualificação atribuída à dedicação à esfera da produção de leis) e que também são bem-sucedidos. Numa afirmação mais generalizável, Pereira e Rennó defendem que diferentes escolhas de carreira determinam diferentes estratégias durante o mandato.

Apesar de superado o debate entre ambição estática e progressiva, percebe-se nos autores a indicação de que os termos do desenvolvimento das carreiras dentro do Congresso brasileiro estariam mais afastados das funções tipicamente legislativas dos parlamentares. Ao avaliar o que propunham os deputados brasileiros entre os anos de 1985 e 1999, Amorim Neto e Santos (2003) estudaram os projetos de lei dos parlamentares que se tornaram leis. Entre as várias observações realizadas, os autores destacam que:

[...] os deputados que conseguem aprovar seus projetos são os que têm a motivação e os recursos políticos necessários para tal. Não é difícil entender por que o acesso

Número de projetos e número de comparecimento a votações, o grau de exposição à mídia (ser membro da Mesa Diretora da Câmara ou ter posição formal de liderança em comissão permanente), a experiência política (número de mandatos), a posição hierárquica dentro do partido e o histórico de votações a favor das proposições do presidente. 
a recursos é necessário para fazer aprovar um projeto. Afinal de contas, a aprovação demanda a árdua tarefa de convencer uma maioria de parlamentares, além da superação dos obstáculos burocráticos e legais impostos pela Constituição e pelo Regimento Interno da Câmara. Desse modo, os deputados que dispõem de mais recursos devem ter maior probabilidade de obter a aprovação dos seus projetos do que os que contam com menos recursos (Amorim Neto e Santos, 2003, p. 671).

Tal afirmação foi corroborada pelos referidos autores ao testarem a hipótese de que a experiência parlamentar (seniority) e a ocupação de postoschave no parlamento são determinantes para a aprovação de leis. Desse modo, podemos afirmar que tais fatores estão incluídos no conjunto de recursos de que o parlamentar deve dispor para alcançar o objetivo pretendido. No entanto, a despeito de ressaltarem o investimento dos deputados na aprovação de seus projetos, os autores atribuem menor importância a eles. Os projetos do Executivo teriam maior impacto econômico e social.

Trazendo uma abordagem diferente das demais, Miguel (2003) buscou enfatizar a construção das carreiras políticas por meio do uso do conceito de capital simbólico de Bourdieu, traduzido em termos de capital político pelo autor quando há um reconhecimento da legitimidade de determinado indivíduo para agir na política (Miguel, 2003, p.121). A lógica é de compreensão simples: quanto maior quantidade de capital político, maior legitimidade e maior desenvoltura para atuar politicamente, permitindo a formação de redes partidárias e extrapartidárias necessárias à busca da renovação do mandado eleitoral.

Miguel procura observar o conjunto da mídia como fonte de obtenção de capital político, na medida em que a visibilidade oferecida pelos meios de comunicação é tida como condição importante para o reconhecimento público ${ }^{4}$. Desse modo, a mídia interferiria na estrutura da carreira política por meio da produção de capital político, particularmente por meio de "atalhos" que permitiriam a postulação de cargos mais elevados e maior acesso às estruturas de poder.

O citado autor conclui que a mídia é importante, mas não é qualquer exposição que pode alavancar carreiras, além do que sua ampla circulação traz elementos de imponderabilidade que podem mudar o jogo político a qualquer

Os trabalhos de Pereira e Rennó $(2001,2007)$ e de Leoni, Pereira e Rennó $(2003)$ tocam na questão da visibilidade de maneira indireta, especialmente por meio das ações dos parlamentares nas arenas orçamentárias e pela posição institucional ocupada nas casas legislativas. 
instante. Apesar de serem facilmente assinalados como relevantes, os efeitos da mídia sobre as carreiras políticas são complexos, obrigando os interessados a observarem mais a forma do que a quantidade de exposição, por exemplo. Nesse caso, o uso e a exposição da mídia terão relação direta com o currículo de cada indivíduo, traduzido pela sua experiência profissional e política pregressas.

As contribuições de todos os pesquisadores aqui comentados são importantes e oferecem-nos excelentes insights para agregar novas abordagens. Não obstante, tomamos a liberdade de apresentar algumas ponderações críticas.

Observando as contribuições dos autores que trabalham o tema carreiras políticas no Brasil, verificamos a dificuldade de se alcançar toda a complexidade do jogo legislativo. Aspectos como os atores mais importantes de cada processo, as emendas apresentadas aos textos em trâmite e os relatórios, entre outros fatores que descrevem e explicam o processo legislativo, não puderam ser aproveitados nos estudos. A tradução desses fatores em termos de variáveis numéricas ou categóricas ainda não foi bem resolvida. A atividade legislativa representa um jogo de múltiplas etapas, idiossincrasias, atores diferenciados e preferências heterogêneas, demandando a associação com outras metodologias para poder ser alcançada. Entendemos que essa questão colaborou de forma relevante para uma compreensão ainda incompleta da atividade legislativa na condução das carreiras políticas, não obstante a existência de variáveis ligadas à arena da produção de leis nos trabalhos publicados.

É interessante observar que o mesmo não aconteceu com as variáveis vinculadas à esfera orçamentária, cuja facilidade na obtenção de dados e informações é ampla e objetiva. Nessa área, os estudos apresentam resultados que parecem mais robustos. Enquanto Pereira e Rennó $(2001,2007)$ conseguiram refinar a questão do credit claiming na arena orçamentária, verificou-se a falta da aplicação da mesma abordagem para as proposições legislativas, ou seja, se ocorre a tentativa de o político capitalizar a atenção ou de se promover em função de projetos de lei.

Amorim Neto e Santos (2003) tangenciam essa questão, mas o recorte realizado por esses autores impõe uma restrição muito importante: para se tornar lei, o projeto deve ser sancionado. Se forem avaliados os vetos, verifica-se que existem vários projetos vetados pelo presidente da República que tinham aspectos abrangentes em termos de políticas públicas, sem entrar aqui na análise de mérito dessas propostas. Significa dizer que, grosso modo, muito do que se converte em lei tem pouca abrangência, mas tal cenário não 
pode ser aplicado ao universo de proposições de autoria de parlamentares que são aprovadas pelo Congresso.

Com relação ao estudo de Miguel (2003), verifica-se o uso de um instrumental mais aplicado aos indivíduos, buscando a interação entre a mídia e cada político, especialmente com relação à construção da imagem de cada um no sentido de analisar a aquisição de capital político para efeitos de carreira. Mas, enquanto o uso da mídia como atalho para esse fim é bem explorado, sabemos que há uma seleção rigorosa por parte de quem cobre as atividades parlamentares acerca daquilo que mais interessa ser passado para o público, sugerindo que temas que mais chamam a atenção do grande público e a valorização de fontes de informação são mais importantes do que o cerne dos debates das centenas de assuntos que são debatidos no dia a dia do Congresso. Não obstante, o construto do capital político nos parece interessante para ser adaptado à arena da produção de leis.

As pesquisas descritas superam a questão dos tipos de ambição política e evidenciam com ênfase a importância da arena orçamentária e da mídia como fatores relevantes na construção de carreiras, ao mesmo tempo em que de certa forma subdimensionam a produção legislativa de iniciativa dos congressistas. Dessa forma, alcançam apenas de maneira subsidiária a arena legislativa como locus relevante para a atuação dos parlamentares. É justamente nesse espaço que procuraremos encaixar o conceito de titular da agenda.

\section{Titulares da agenda: argumentos teóricos}

Como foi observado, predomina a tese de que a forte concentração de poderes legislativos nas mãos da Presidência e a centralização do processo decisório no interior do Legislativo tornam a ação dos congressistas dedicados à arena da produção de leis praticamente inócua. Essa perspectiva é reforçada por Santos:

[O] aumento das prerrogativas do Executivo não define a intensidade das preferências, a verdadeira responsável pela paralisia decisória. Apenas retira do Legislativo a capacidade de contribuir de forma efetiva para a montagem e solução da agenda política brasileira (Santos, 1997, p. 486).

A despeito dessa forma contundente de observar a atuação dos parlamentares, Santos (1997) admite que os políticos possuem uma gama vasta 
de estratégias para obter e defender seus mandatos e que o Congresso é composto por atores com preferências bastante variadas. Assim, mesmo um processo legislativo mediado por um presidente poderoso e por partidos fortes dentro do Congresso pode oferecer oportunidades para ações parlamentares com interesses específicos. Essa seria a licença conferida para a ação individual: o fato de proporem projetos de lei e, mais, de trabalharem na análise de vários outros, indica que é possível encontrar caminhos que, potencialmente, projetem a ação do parlamentar.

O reconhecimento de sua atuação na aprovação de uma proposta legislativa, seja como autor ou como relator, coloca o político em uma posição de destaque frente aos eleitores, assim como em relação ao seu grupo partidário (coalizão governamental/oposição) ou temático (frentes parlamentares formalizadas ou grupos de interesse organizados vinculados ao parlamentar $)^{5}$.

Dessa forma, torna-se relevante fazer parte dos processos decisórios dos projetos de lei, não apenas no âmbito dos plenários das casas legislativas mas também nas comissões, especialmente quando o parlamentar está à frente de determinada proposição legislativa, responsabilizando-se pelas negociações em torno do texto e servindo de ponto de referência para grupos organizados, enfim, aquele que está cuidando da matéria em tramitação.

Nesse âmbito, ganha significado o conceito de titular da agenda, entendido como o parlamentar que, em determinadas matérias, centraliza articulações políticas entre os demais parlamentares, o Poder Executivo e representantes do empresariado e da sociedade civil organizada, em atuação que tende a ter repercussões relevantes nos textos legais produzidos.

Cabe dizer que a centralização das negociações políticas das proposições legislativas em debate não ocorre apenas no exercício da função de relatoria.

\footnotetext{
Segundo Araújo e Silva (2011), as limitações inerentes às normas gerais a cargo da União praticamente inviabilizam a existência de leis não insertas na arena orçamentária que se direcionem a estados ou municípios específicos. Com um ambiente de apresentação dos projetos menos afetado pelo pork na arena legislativa, acaba-se aplicando os efeitos de caráter distributivista a vinculações do ponto de vista de corporações (servidores públicos, categorias profissionais específicas etc.), de setores econômicos ou de grupos de interesse difuso, mas que geram possibilidade de ganhos positivos em termos da imagem do parlamentar. Nesse sentido, assume relevância a questão da conexão eleitoral por meio da intermediação dos grupos de interesse (Lohman, 1998, 2003). Esses agentes têm maior capacidade de analisar quais canais são mais permeáveis para a introdução de suas demandas em arenas decisórias (parlamentares ou governo). É importante notar que tais grupos não cessam suas atividades a partir do momento em que conseguem o"patrocínio"de um parlamentar para encampar seus objetivos, ou mesmo a simpatia de setores do Poder Executivo. A atuação é incessante e busca sempre o locus mais favorável a cada momento.
} 
Nem todos os relatores conseguem assumir efetivamente o papel de titular da agenda e há outros tipos de atores que podem ter esse tipo de atuação, como parlamentares na coordenação de grupos de trabalho, alguns autores de proposições legislativas ou parlamentares especializados tematicamente que se firmam como negociadores.

Julgamos que a figura do titular da agenda é mais abrangente que a perspectiva da função de advisor ad hoc dos parlamentares, citada por Santos e Almeida (2005), uma vez que ele tende a representar também uma espécie de policy broker (Sabatier e Jenkins-Smith, 1993, 1999) junto ao eleitorado e aos grupos interessados, minimizando o grau de conflito entre os atores partícipes dos processos decisórios e contribuindo para a concretização das decisões.

Verificar como e em que condições um parlamentar se torna um titular da agenda proporciona uma visão mais detalhada da dinâmica da relação entre os poderes Legislativo e Executivo, na medida em que se explora por outro prisma o processo legislativo movido pelos parlamentares, e impacta também a análise da construção das carreiras políticas.

Cabe dizer que a condição de titular da agenda também pode alçar o parlamentar a um relacionamento especial com o Poder Executivo, na medida em que a proposição da qual está cuidando chame a atenção desse ator político, poderoso e com extensa capacidade de articulação. É nesse ponto que se estabelece relação entre a figura do titular da agenda e o fenômeno da apropriação da agenda do Legislativo pelo Executivo.

A apropriação é verificada pelo fato de que muitos projetos de lei ou medidas provisórias do governo são inspirados em propostas que tramitam no parlamento, contrariando a noção do senso comum de que as matérias de interesse do Executivo se originaram exclusivamente dos órgãos da administração pública ${ }^{6}$. Excetuando-se as proposições caracterizadas como de iniciativa exclusiva do presidente da República, constata-se que, no período de 1995 a 2010, 18,5\% das medidas provisórias e 40\% dos projetos de lei do Executivo surgiram por meio da apropriação da agenda do Legislativo (Araújo e Silva, $2011)^{7}$. A apropriação tem diferentes explicações, entre elas a aproximação com as demandas veiculadas pelos parlamentares, e ocorre em situações

Essa prática pode assumir diferentes feições em continuum crescente que reflete diferentes graus de apropriação: abordagem de temáticas já trabalhadas no âmbito do Legislativo, adoção de ideias semelhantes ou até mesmo cópias literais de dispositivos de proposições legislativas em trâmite (Silva e Araújo, 2010a, 2010b).

Ver: https://docs.google.com/open?id=0B6RNvZn_uRWJNTZiWnNYNEXUMDJsNnNIY1 Juck5IZw. 
quer de coordenação quer de conflito entre o Executivo e o parlamentar a ela submetido, mas seu detalhamento extrapola os objetivos deste trabalho.

Foi justamente pela percepção da importância que o parlamentar condutor da matéria sujeita à apropriação tinha ao longo do processo que Silva e Araújo (2010a, 2010b) puderam notar o papel do titular da agenda. No estudo então realizado, o titular da agenda surgia como o autor da proposta sujeita a apropriação ou como relator que tivesse produzido parecer sobre a proposta sujeita à apropriação. $\mathrm{O}$ conceito ganhou agora contornos mais nítidos, na forma acima apresentada.

Se o autor ou relator da proposta apropriada conseguirem tirar proveito do processo de apropriação, tenderão a ter ganhos de capital político e em termos de peso em futuras negociações. Dessa forma, o fenômeno da apropriação pode ser, também, uma oportunidade de aquisição de mais recursos políticos, com implicações em termos de carreiras.

Figura 1. Relação entre o capital político do titular da agenda e a apropriação

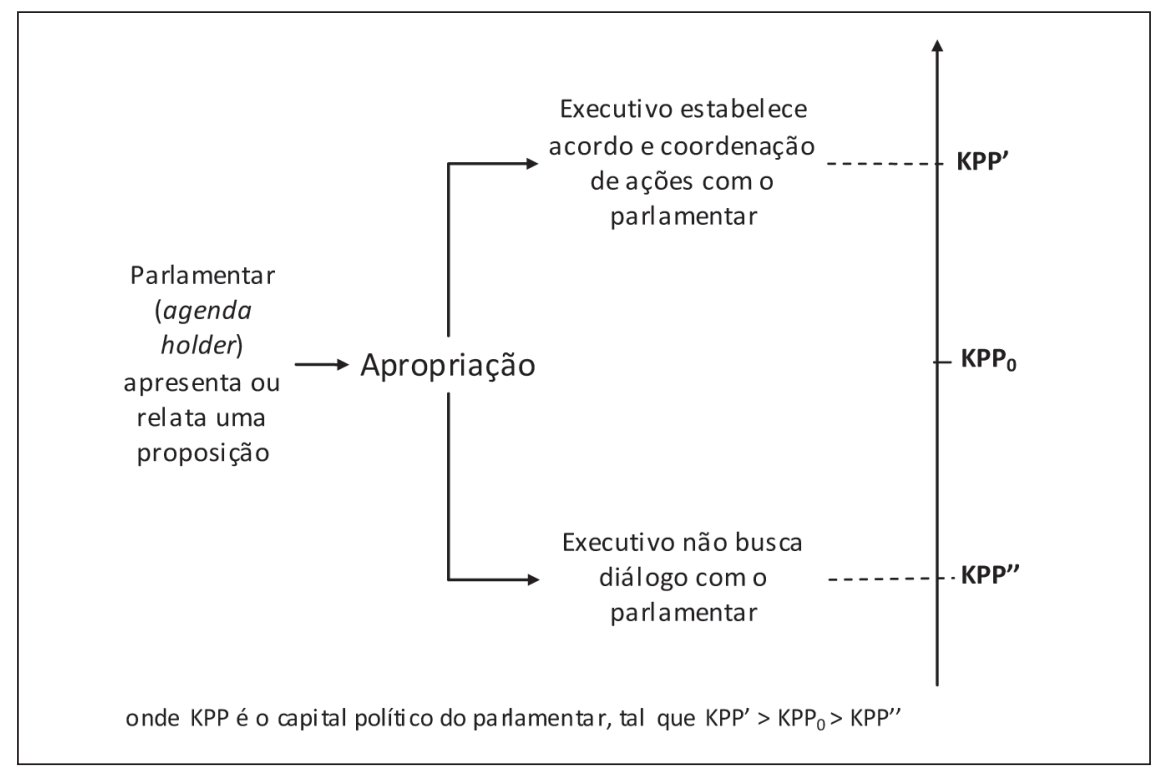

No momento em que o parlamentar investe na apresentação do projeto de lei, numa oportunidade de relatoria ou, na ausência dessas condições, na defesa de pontos de vista bem fundamentados relativos ao trâmite de 
proposições, consideramos que há um investimento no seu capital político $\left(\mathrm{KPP}_{0}\right)$, dados os pressupostos de conexão eleitoral e de carreira política. Consideramos tal iniciativa como a tentativa de obter credit claiming. No momento em que ocorre a apropriação, surgem duas possibilidades. Se o parlamentar foi convidado a participar ou a negociar o texto ou conteúdo da nova proposição do Executivo, infere-se um ganho de capital político (KPP'), na medida em que se abrem novas possibilidades de carreira política perante o próprio governo, a mídia e, consequentemente, o eleitorado. Caso contrário, haverá grandes possibilidades de perda de capital político (KPP”), uma vez que a apropriação somente renderia credit claiming aos elementos do governo.

Observa-se que o parlamentar eleva suas expectativas de ganho de capital político com a perspectiva de se beneficiar da apropriação. Percebem-se dois momentos da atuação do parlamentar sobre os projetos de lei. O primeiro é o "investimento" na conexão eleitoral, fruto de suas ações junto a grupos de eleitores ou grupos de interesse, podendo, dependendo da matéria, fazer com que o parlamentar também possa contar com maior acessibilidade a mais recursos políticos, na medida em que (i) pode ser visto como importante interlocutor daquela matéria, (ii) pode ganhar expressão dentro do seu partido político e, em decorrência, (iii) ser nomeado para cargos no Legislativo (presidência de comissões, mesas diretoras das casas legislativas etc.).

Em um segundo momento, quando manifesto o interesse do Executivo pela proposta, e, consequentemente, havendo chances reais de ocorrer a apropriação, o parlamentar eleva seu capital político, ampliando suas possibilidades de pleitear ou indicar cargos no Executivo e ter mais acesso à aprovação e liberação de emendas no orçamento, assim como um maior potencial de exposição positiva em relação à mídia. Nesse caso, o fenômeno da apropriação representaria uma relevante janela de oportunidade para potencializar os ganhos de capital político, justamente pela facilidade de o Executivo mobilizar agendas de interesse político e midiático.

Desse modo, o estudo do fenômeno da apropriação faz referência direta entre as proposições legislativas iniciadas no Congresso e carreiras políticas, ressaltando fortes possibilidades de mútuo benefício para atores do parlamento e do Executivo na hipótese da aproximação de suas preferências.

Pelo potencial de a apropriação evidenciar a efetividade dos parlamentares na produção das leis e, também, pelo entendimento de que a tarefa de legislar pode fortalecer as carreiras políticas, utilizamos como recorte 
de estudo as situações em que ocorreu a apropriação retratadas por Silva e Araújo (2010a, 2010b). Ressalte-se que vários outros recortes na dinâmica do Legislativo podem ser efetivados para o estudo da atuação dos titulares da agenda, independentes do fenômeno da apropriação.

\section{Atuação dos titulares da agenda}

Assume-se o pressuposto de que as leis que realmente são aplicadas são resultado de processos de articulação estruturados e solucionados de forma competente do ponto de vista político, o que tende a envolver atores do Legislativo e do Executivo. Nesse quadro, os titulares da agenda têm papel ainda não devidamente estudado. Eles influenciam o processo legislativo, sobretudo, ao estabelecer ligações entre o mundo político, as áreas técnicas e a sociedade civil organizada.

Os titulares da agenda podem atuar em diferentes estágios do processo legislativo. Na maioria das vezes, parlamentares com perfil para esse tipo de atuação serão selecionados como relatores de processos legislativos ou para funções equiparadas à relatoria, mas, como já referido, encontram-se autores de projetos de lei que centralizam a articulação política e, também, parlamentares especializados em temas específicos que funcionam como ponto focal nos processos decisórios, independentemente de relatoria ou autoria de proposições legislativas.

O senador Paulo Paim (PT/RS) é exemplo de parlamentar que, reconhecidamente, atrai demandas políticas em torno dos temas afetos à questão trabalhista, especialmente nos debates sobre o reajuste anual do salário mínimo. Ele é visto como um dos responsáveis pelo assunto no Congresso Nacional por sindicatos e associações e pela imprensa. O Executivo sabe que esse parlamentar participará das negociações em relação ao salário mínimo, com posicionamento crítico mesmo no período em que seu partido esteja no poder.

Outro exemplo ilustrativo é o da senadora Kátia Abreu (PSD/TO). A parlamentar, que desde 2008 também preside a Confederação Nacional da Agricultura e Pecuária (CNA), tende a coordenar as articulações políticas em torno dos principais temas afetos a esse setor. A bancada ruralista é numerosa, com vários parlamentares que podem ser considerados especializados, mas seus membros não parecem ter o papel de articulação da senadora.

Contudo, há vários parlamentares que atuam como titular da agenda que não têm essa ligação com temas determinados tornada pública pela mídia 
como ocorre com os citados parlamentares. No esforço de identificar esses casos, adotamos como eixo de análise os casos de apropriação da agenda do Legislativo, previamente levantados nos estudos de Silva e Araújo (2010a, 2010b). A partir deles, serão complementadas informações sobre alguns processos conexos, bem como sobre as carreiras dos atores envolvidos. A importância atribuída a esses casos no estudo anterior sobre a apropriação refletese na sua contribuição para rastrearmos a atuação dos titulares da agenda e verificarmos a conexão dessa condição para as respectivas carreiras políticas.

\section{Estudos de caso}

Considera-se que os processos legislativos em que ficou caracterizada a apropriação da agenda do Legislativo referem-se a proposições cuja relevância pode ser depreendida do próprio fato de terem atraído o interesse governamental. Elas tenderão, também, a estar associadas a quadros de relação entre os poderes Executivo e Legislativo, e de negociação política, que merecem ser descritos e compreendidos.

Nos dados referentes aos processos de apropriação detalhados por Silva e Araújo (2010a, 2010b), são encontradas indicações de parlamentares com perfil de articuladores e, também, de articuladores com especialização temática, como se mostrará na sequência. É interessante notar que esses casos indicaram titulares da agenda de variados vínculos partidários.

Enfatize-se que se trata apenas de uma primeira seleção de parlamentares com essas características, realizada a partir de informações disponíveis sobre determinados processos legislativos, que foram complementadas no que se refere aos dados sobre carreiras políticas e produção legislativa. Não obstante, a seleção trazida pelos casos de apropriação indica a relevância dos assuntos tratados pelos parlamentares, bem como a conexão temática e política que envolve os titulares da agenda em mais de uma proposição legislativa.

O tema do meio ambiente tem sido objeto de vários casos de apropriação. Um deles refere-se à Lei Complementar n. 140/2011, que dispõe sobre a cooperação entre União, estados, Distrito Federal e municípios no campo da política ambiental.

Em 2003, o deputado Sarney Filho (PV/MA) apresentou projeto de lei complementar ${ }^{8}$ dispondo sobre a forma de cooperação entre os entes federa-

Ver processo referente ao Projeto de Lei Complementar (PLP) n. 12/2003 na Câmara dos Deputados e ao Projeto de Lei da Câmara (PLC) n. 01/2010 no Senado Federal. 
dos para a execução das atribuições comuns inclusas no art. 23 da Constituição Federal, no que se refere a meio ambiente. O projeto manteve-se em tramitação lenta até que, em 2007, foi enviado ao Legislativo projeto assinado pelo presidente da República com a mesma finalidade, no âmbito das medidas legislativas relacionadas ao Programa de Aceleração do Crescimento (PAC) ${ }^{9}$.

O deputado Sarney Filho esteve envolvido diretamente em todo o processo de negociação sobre essa matéria. A ideia e a autoria da Lei Complementar n. 140/2011, assim, podem ser imputadas ao deputado, mesmo que ele próprio explicite desagrado em relação a uma parte do texto aprovado. Poucos parlamentares poderão colocar em seu currículo a aprovação de uma lei complementar. A aprovação dessa lei, na verdade, corrobora vários anos de atuação especializada desse parlamentar.

Não obstante o histórico familiar constituir fator a ser necessariamente ponderado na análise da carreira política do deputado Sarney Filho, em oito mandatos consecutivos como deputado federal ${ }^{10}$, ele consolidou uma atuação importante direcionada à questão ambiental. Tem-se mantido sempre como titular da comissão de meio ambiente da Câmara, presidiu essa câmara técnica no período 1995/1996 e a preside no ano de 2012, foi ministro do Meio Ambiente entre 1999 e 2002, atuou várias vezes como líder do Partido Verde e tem coordenado a Frente Parlamentar Ambientalista desde sua criação. Nessa condição, participa de praticamente todas as negociações de relevo nesse campo, caracterizando-se como um titular da agenda. No banco de dados da Câmara, constam 52 projetos de lei ordinária apresentados por ele, e 121 processos relatados ${ }^{11}$. Esse posicionamento do parlamentar dentro do Congresso o qualifica como uma voz ativa perante os grupos interessados, os demais partidos e também perante o Executivo.

Além do projeto de lei complementar supracitado, há outra proposta de autoria do deputado Sarney Filho que pode ser considerada como tendo sido objeto de apropriação da agenda do Legislativo: o projeto que gerou

Em um processo legislativo com mais de uma proposição, a proposta mais antiga ou aquela já aprovada por uma das casas legislativas tramita como principal. As demais são consideradas apensadas. Trata-se de uma opção regimental para organização processual. Não há prioridade para a aprovação da proposição principal em relação às outras inclusas no mesmo processo.

10 Legislaturas 1983-1987, 1987-1991, 1991-1995, 1995-1999, 1999-2003, 2003-2007, 2007-2011 e 2011-2015.

1 As informações sobre número de proposições apresentadas e relatadas constantes neste trabalho foram coletadas em 10 de janeiro de 2012. 
a Lei n. 12.187/2009, que institui a Política Nacional sobre Mudança do Clima. Em 2007, o parlamentar havia apresentado projeto de lei ${ }^{12}$ dispondo sobre a obrigatoriedade da adoção de medidas, por parte do poder público, objetivando a redução das emissões dos gases responsáveis pelo efeito estufa. Foi apensado a esse projeto um conjunto de outras proposições similares, incluindo uma de autoria do presidente da República, datada de 2008.

Atuou na relatoria do referido processo o deputado Antônio Carlos Mendes Thame (PSDB/SP). Esse parlamentar era autor de proposta que dispunha sobre a Política Nacional de Mudanças Climáticas, apresentada em 2007, a qual, por questões regimentais ${ }^{13}$, tramitava de forma independente. Essa autoria provavelmente justifica o fato de esse parlamentar, membro da oposição, ter sido nomeado relator de um processo que interessava diretamente ao Executivo. Outra razão que reforça essa escolha está na especialização temática do deputado Thame.

Deputado federal com seis mandatos ${ }^{14}$, ele também tem permanecido em várias sessões legislativas como titular da comissão de meio ambiente da Câmara. Professor universitário da área da agronomia com base eleitoral em região sucroalcooleira, o deputado Thame dedica atenção especial às interfaces entre meio ambiente e agricultura, e entre meio ambiente e energia. Coordena ainda o grupo de trabalho sobre energias renováveis da Frente Parlamentar Ambientalista. No banco de dados da Câmara, constam 312 projetos de lei ordinária apresentados por ele, e 57 processos relatados.

Outro caso interessante que também envolve o deputado Thame envolve a questão da importação de pneus. Em 2005, foi apresentado projeto de lei de autoria do presidente da República instituindo o Sistema de Gestão Ambientalmente Sustentável de Pneus ${ }^{15}$. Havia propostas anteriores, apresentadas por parlamentares, relacionadas a esse assunto. O deputado Thame era autor

12 Ver processo referente ao Projeto de Lei (PL) n. 18/2007 na Câmara dos Deputados e ao Projeto de Lei da Câmara (PLC) n. 283/2009 no Senado Federal.

13 Ver processo referente ao PL n. 261/2007 na Câmara dos Deputados. Como essa proposição correu sob o regime do poder conclusivo das comissões, regimentalmente não cabe apensação de outras propostas depois que a primeira comissão de mérito se manifesta sobre a matéria. Essa é a razão que explica porque o projeto de lei do Executivo foi apensado ao PL n. 18/2007 e não ao PL n. 261/2007.

${ }^{4}$ Legislaturas 1987-1991, 1991-1995, 1999-2003, 2003-2007, 2007-2011 e 2011-2015.

15 Ver processo referente ao PL n. 6.136/2005 na Câmara dos Deputados, posteriormente apensado ao PL n. 449/2003. Esse tema somente foi decidido alguns anos depois, com a entrada em vigor da Lei n. 12.305/2010 (Lei dos Resíduos Sólidos). Houve também, em 2009, decisão do Supremo Tribunal Federal (STF) que vedou a importação de pneus usados. 
de um desses projetos, datado de 2003, que vedava a importação de bens usados. A proposição do Executivo foi apensada à proposta do deputado Thame apenas em 2005, a partir da aprovação de requerimento nesse sentido apresentado pelo próprio parlamentar. Considera-se que o deputado Thame também é um titular da agenda especializado em meio ambiente, surgindo em pelo menos duas situações de apropriação da agenda do Legislativo claramente caracterizadas.

$\mathrm{O}$ vínculo partidário constitui fator a ser necessariamente ponderado quando se analisa o papel do parlamentar em negociações políticas. Com o controle político pelo Executivo associado a nosso presidencialismo de coalizão, tende a ser difícil para o parlamentar que não integra a base do governo assumir relatorias ou outras funções formalizadas de coordenação em processos importantes. Não obstante, como a coalizão governamental não detém controle pleno das comissões e de outros órgãos das casas legislativas, essas situações ocorrem, sendo potencializadas pela especialização dos parlamentares quanto aos temas em pauta.

Nesse sentido, os estudos de Silva e Araújo (2010a, 2010b) sobre apropriação da agenda do Legislativo descrevem um caso em que a atuação de parlamentar da oposição como articulador político desperta interesse.

Parlamentares que atuam na questão urbana e técnicos do setor têm defendido a aprovação da Lei de Responsabilidade Territorial Urbana (LRTU), em complementação ao Estatuto da Cidade ${ }^{16}$. O processo legislativo ${ }^{17}$ que lida com esse assunto, reunindo em trâmite conjunto dezessete projetos de lei de autoria de parlamentares, já ultrapassou a etapa das comissões na Câmara dos Deputados. Foi aprovado na forma de substitutivo elaborado no âmbito de comissão especial, que teve como último relator o deputado Renato Amary $(\mathrm{PMDB} / \mathrm{SP})^{18}$, e está pronto para a votação em plenário desde o final de 2007. Esse texto aborda regras para os novos parcelamentos urbanos e para a regularização fundiária de favelas e outras ocupações irregulares em cidades.

O deputado Amary, que não se reelegeu para o período 2011-2015, era então deputado federal de primeiro mandato, mas político experiente, com passagem pela Assembleia Legislativa do Estado de São Paulo e dois

${ }^{6}$ Lei n. $10.257 / 2001$

7 Ver processo referente ao PL n. 3.057/2000 e apensos na Câmara dos Deputados.

18 O Deputado Amary filiou-se ao PMDB em março de 2011. Quando atuou na relatoria da LRTU, era filiado ao PSDB. 
mandatos como prefeito de Sorocaba (SP), cidade com mais de quinhentos mil habitantes. Além disso, é empresário do setor imobiliário, podendo em razão disso ser considerado especializado no tema da LRTU. A capacidade de articulação política desse parlamentar ficou evidenciada pela aprovação de seu substitutivo na comissão especial. Dois relatores anteriores haviam fracassado nesse intento. Trata-se de um processo complexo, que envolve conflitos entre o setor empresarial, o Fórum Nacional de Reforma Urbana, o Ministério das Cidades, as entidades ambientalistas, os órgãos de defesa do consumidor e outros atores.

O relator não teve força política suficiente, todavia, para assegurar a colocação de seu texto em pauta no plenário. Avaliamos que, pelo menos parcialmente, essa situação decorreu da apropriação ocorrida de conteúdo presente no substitutivo da LRTU. Quando foi adotada a medida provisória relativa ao programa Minha Casa, Minha Vida (PMCMV) ${ }^{19}$, o Poder Executivo inseriu no texto um capítulo relativo à regularização fundiária em áreas urbanas com base nas discussões organizadas pelo deputado Amary sobre a LRTU. A apropriação de parte do texto por meio de sua inserção na medida provisória que gerou a Lei do PMCMV esvaziou politicamente as discussões sobre a LRTU, reduzindo as chances de sua aprovação.

Assim, apesar de ter atuado como um titular da agenda nos debates sobre a LRTU, o deputado Amary não foi bem-sucedido na fase final do processo na Câmara. A condição de parlamentar oposicionista na coordenação de tema com relevante repercussão eleitoral pode ter levado o Executivo a adotar a citada medida provisória, chamando para si a autoria das normas sobre regularização. Perceba-se ainda que um sucesso nesse campo, pelo menos em tese, poderia ter contribuído positivamente para a reeleição do parlamentar. O pouco tempo de Câmara dos Deputados do relator é outro aspecto que deve ser levado em consideração, uma vez não ter tido oportunidade de ter construído sua rede de relacionamentos intra e interpartidários necessários para fazer avançar uma proposição. Trata-se de um caso que evidencia perda de capital político em decorrência da apropriação da agenda pelo Executivo.

É interessante notar que o processo que gerou a Lei do PMCMV nos traz a oportunidade de verificar a atuação de outro titular da agenda. Apesar de não ter a característica da especialização temática, o deputado Henrique Eduardo

19 Ver Medida Provisória (MPV) n. 459/2009 e Lei n. 11.977/2009. 
Alves (PMDB/RN) foi escolhido relator da medida provisória, que recebeu na Câmara dos Deputados 307 emendas de parlamentares. Dessas, 99 foram incorporadas no projeto de lei de conversão do relator aprovado no plenário, evidenciando o trabalho do relator como articulador de demandas políticas.

O deputado Henrique Alves tem o histórico familiar que lhe tornou favorável a carreira política, além de ser um veterano na Câmara dos Deputados, com onze mandatos ${ }^{20}$. No banco de dados da Câmara, constam 450 projetos de lei ordinária apresentados por ele, e 56 processos relatados, vários deles relativos a autorizações para exploração de serviços de radiodifusão.

As relatorias desse parlamentar têm alcançado processos de maior relevância política nos últimos anos. Com isso, tende a consolidar o papel de titular da agenda, condição essa que também lhe reforça o status de liderança partidária e congressual. Note-se que não se está colocando aqui a articulação política que decorre diretamente do exercício da liderança partidária ou de governo.

Além da Lei do PMCMV, outro processo relevante em que o deputado Henrique Alves foi chamado a atuar foi o dos debates sobre o Pré-Sal, caso também detectado de apropriação da agenda do Legislativo. O projeto de lei de autoria do presidente da República com normas sobre a exploração e a produção de petróleo, de gás natural e de outros hidrocarbonetos fluidos em áreas do Pré-Sal ${ }^{21}$, enviado ao Congresso Nacional em 2009, foi apensado a outro de autoria parlamentar, datado de 2007, que dispunha sobre contratos de partilha para exploração e produção de petróleo e gás natural.

O relatório da comissão especial constituída para análise dessa matéria, elaborado pelo deputado Henrique Alves, refletia um trabalho de ampla articulação política, incluindo o governo. Contudo, debates posteriores fizeram com que esse processo fosse fundido ao referente ao fundo social ${ }^{22}$, com resultado final que repercutiu negativamente sobre os estados produtores de petróleo, contrariando acordos anteriormente firmados com o Executivo. Em razão disso, o presidente vetou artigo da Lei n. 12.351/2010 e reabriu o debate sobre os royalties do Pré-Sal, por meio da apresentação de outro

\footnotetext{
20 Legislaturas 1971-1975, 1975-1979, 1979-1983, 1983-1987, 1987-1991, 1991-1995, 1995-1999, 19992003, 2003-2007, 2007-2011 e 2011-2015.

${ }^{21}$ Ver processo referente ao PL n. 5.938/2009 na Câmara dos Deputados, apensado ao PL n. 2.502/2007. No Senado Federal, ver PLC n. 16/2010.

22 Ver processo referente ao PL n. 5.940/2009 na Câmara dos Deputados e ao PLC n. 7/2010 no Senado Federal.
} 
projeto de sua autoria ${ }^{23}$, com texto bastante similar ao constante no relatório construído pelo deputado Henrique Alves no processo anterior.

Silva e Araújo (2010a, 2010b) também analisaram uma situação na qual fica clara a indicação de mudança de status político do parlamentar, apontando para a progressividade na configuração do titular da agenda, está no trabalho do deputado Asdrúbal Bentes (PMDB/PA) quanto ao tema da regularização fundiária em áreas rurais.

Asdrúbal Bentes é deputado com seis mandatos ${ }^{24}$, com atuação direcionada a assuntos relacionados à Amazônia. Advogado, foi presidente do Grupo Executivo das Terras do Araguaia-Tocantins (Getat) e superintendente do Instituto Nacional de Colonização e Reforma Agrária (Incra) no Pará, o que denota especialização em questões fundiárias. No banco de dados da Câmara, constam apenas quinze projetos de lei ordinária apresentados por ele, mas 151 processos relatados, um número significativo.

O deputado Bentes foi membro da comissão especial responsável pela análise da Lei de Gestão das Florestas Públicas ${ }^{25}$, que tem as concessões florestais para a iniciativa privada como principal objeto. Após a entrada em vigor da referida lei, o parlamentar apresentou projeto ${ }^{26}$ com alteração pontual na Lei de Licitações ${ }^{27}$. Na visão do parlamentar, a Lei de Gestão das Florestas Públicas não havia solucionado o problema da ocupação irregular das terras na Amazônia por pessoas físicas, pequenos e médios produtores rurais.

Pouco tempo depois, foi adotada medida provisória ${ }^{28}$ que reproduzia inteiramente o projeto do deputado Bentes. $\mathrm{O}$ parlamentar atuou como relator desse processo, que gerou a Lei n. 11.763/2008, em quadro que evidencia negociação e coordenação com o Executivo. Na sequência, o mesmo parlamentar atuou na relatoria da medida provisória ${ }^{29}$ base da Lei n. 11.952/2009, que traz a disciplina da regularização fundiária de ocupações em terras da União na Amazônia Legal, demanda política antiga do deputado Bentes e de outros parlamentares da região.

23 Ver processo referente ao PL n. 8.051/2010 na Câmara dos Deputados, apensado ao PL n. 1.618/2003.

24 Legislaturas 1987-1991, 1995-1999, 1999-2003, 2003-2007, 2007-2011 e 2011-2015.

25 Lei $n .11 .284 / 2006$.

${ }^{26}$ Ver processo referente ao PL n. 2.278/2007 na Câmara dos Deputados.

27 Lei $n .8 .666 / 1993$.

28 Ver MPV n. 422/2008.

29 Ver MPV n. 458/2008. 
Observa-se, assim, que mesmo um parlamentar com atuação política regionalizada e com poucos projetos de lei apresentados pode ter propostas apropriadas pelo Executivo, no caso a partir de relações de cooperação, bem como funcionar como ponto focal de determinados temas no Congresso Nacional. Mantida essa atuação do deputado Bentes, estará caracterizada sua condição de titular da agenda especializado tematicamente. Além disso, seu perfil biográfico e a atuação nesses processos indica claramente a obtenção de credit claiming e, portanto, ganho de capital político perante o eleitorado e perante suas relações partidárias.

Outro caso de parlamentar envolvido em situação de apropriação de agenda que merece comentários é o de Eduardo Jorge (PV/SP), secretário do Verde e Meio Ambiente do município de São Paulo desde 2005. Médico sanitarista, organizador dos primeiros conselhos populares de saúde, esse político foi secretário de saúde do município de São Paulo nos governos de Luiza Erundina e Marta Suplicy, deputado estadual ${ }^{30}$ e deputado federal ${ }^{31}$, à época pelo Partido dos Trabalhadores. Desenvolveu trabalho de destaque nos debates da Assembleia Nacional Constituinte sobre saúde e seguridade social (Oliveira, 2005), mostrando características de um titular da agenda.

A apropriação da agenda relacionada a proposta do ex-deputado Eduardo Jorge, analisada por Silva e Araújo (2010a, 2010b), corrobora a relevância da atuação desse político na área da saúde.

A Lei n. 10.858/2004, que dispõe sobre a disponibilização de medicamentos pela Fundação Oswaldo Cruz, visando assegurar à população o acesso a produtos básicos e essenciais à saúde a baixo custo, teve origem em medida provisória de dezembro de $2003^{32}$. O Decreto n. 5.090/2004, que regulamentou essa lei, instituiu o programa Farmácia Popular do Brasil.

Pela análise dos respectivos conteúdos, fica evidenciado que a medida provisória e seu regulamento foram inspirados em projeto de lei ${ }^{33}$ de autoria do então deputado Eduardo Jorge, datado de 1994. Essa proposição, que regulava a criação das farmácias populares, passou por tramitação lenta na Câmara e foi aprovada e remetida ao Senado apenas em maio de 2003, onde foi rejeitada exatamente em razão da existência da Lei n. 10.858/2004.

30 Legislatura 1983-1987.

31 Legislaturas 1987-1991, 1991-1995, 1995-1999 e 1999-2003.

32 Ver MPV n. 154/2003.

33 Ver processo referente ao PL n. 4.702/1994 na Câmara dos Deputados e ao PLC n. 30/2003 no Senado Federal. 
Cabe notar que Eduardo Jorge ampliou seu campo de atuação para abarcar também a questão ambiental e, com esse trabalho mais amplo, vem-se mantendo em atividade política como titular de cargos na administração pública. Embora sua trajetória não tenha indicado manutenção de carreira no Congresso, ela demonstra continuidade na carreira política.

Outro exemplo de articulação política combinada com especialização temática, incluso em situação de apropriação identificada por Silva e Araújo (2010a, 2010b), está na deputada Fátima Bezerra (PT/RN). Pedagoga, com dois mandatos como deputada estadual ${ }^{34}$ e três ${ }^{35}$ como deputada federal, a deputada Fátima Bezerra tem-se mantido como titular da comissão de educação e cultura da Câmara e atuado, essencialmente, em processos relacionados a esses temas. No banco de dados da Câmara, constam 28 projetos de lei ordinária apresentados por ela, e 126 processos relatados.

A Lei n. 11.494/2007, que regulamentou o Fundo de Manutenção e Desenvolvimento da Educação Básica e de Valorização dos Profissionais da Educação (Fundeb) é oriunda de medida provisória ${ }^{36}$. Parte do conteúdo dessa medida provisória foi baseada em proposições em trâmite no Legislativo. Como exemplo, tem-se a questão do controle social, trabalhada a partir de substitutivos ao Projeto de Lei n. 241/1999, de autoria do deputado Professor Luizinho (PT/SP), apresentados na comissão de educação e cultura e na comissão de constituição e justiça, respectivamente pelo deputado Gastão Vieira (PMDB/MA) e pela deputada Fátima Bezerra. O controle social é elemento importante dessa legislação. Em sua análise da referida lei, Sena afirma que "no aspecto do controle social, as fragilidades reveladas no período do Fundef levaram ao aperfeiçoamento das regras referentes aos conselhos, acerca de sua autonomia, democracia, composição e instrumentos" (Sena, 2008, p. 321). Em relação de cooperação com o Executivo, a deputada Fátima Bezerra foi relatora da medida provisória e articulou os acordos ocorridos no processo. Considera-se que essa parlamentar também é uma titular da agenda, especializada em educação e cultura. Ela mantém sua condição de parlamentar no Congresso.

34 Legislaturas 1995-1999 e 1999-2003.

35 Legislaturas 2003-2007, 2007-2011 e 2011-2015.

36 Ver MPV n. 339/2006. 


\section{Aspectos mais importantes revelados pelos estudos de caso}

Foi observado nos processos estudados que o titular da agenda não trabalha como agente neutro nos processos decisórios de que participa. Ele vai além, contudo, da defesa de seus próprios posicionamentos, ou da defesa dos interesses de seu partido político, ao promover negociações entre diferentes atores envolvidos nas disputas em pauta.

Os casos indicam que ser titular da agenda representa, para o parlamentar que decide investir na política por meio da atuação na arena da produção de leis, uma importante condição de aquisição de capital político. Pode significar um recurso adicional para alavancar a carreira política para alguns, como aponta o exemplo do deputado Asdrúbal Bentes, bem como para a sustentação da situação alcançada por outros, como o deputado Sarney Filho.

As informações colhidas e analisadas sugerem que, para ser e se estabelecer ao longo do tempo como titular da agenda, são relevantes (i) o passado do indivíduo, sua biografia, suas possíveis especializações (que aqui também tratamos como o tema focalizado pelo parlamentar); (ii) a seniority no Congresso; e (iii) sua capacidade de negociação. Verificamos que esses elementos não funcionaram de forma estanque nos casos estudados, mas de maneira articulada.

Com relação à biografia, deve-se levar em conta que existem muitos fatores intervenientes e também relevantes, tal como a forma de exposição à mídia, como bem ressaltou Miguel (2003). O passado dos indivíduos pode ser elemento de percepção da capacidade negocial, na medida em que o exercício de posições de liderança partidária são indícios de que ela existe. Essa articulação foi verificada nos casos estudados. A percepção da seniority indica que ela é sem dúvida relevante, mas não basta observar apenas o número de mandatos. Deve-se também dar atenção para a forma como esses mandatos transcorreram, como se buscou fazer neste trabalho.

Além de alavancar a carreira, a condição de titular da agenda exige um investimento prévio em capital político, pois, para assim ser considerado, demanda-se do parlamentar a construção de uma rede de relacionamentos no Congresso Nacional, que pode tanto ser alcançada pela especialidade temática, que predominou nos casos estudados, como pela habilidade de negociação com seus pares, do seu partido e dos demais. Dificilmente um parlamentar inexperiente chegará a essa condição no seu primeiro mandato. 
No exemplo do deputado Renato Amary, apesar de sua atuação como titular da agenda em um processo legislativo relevante, o fato de ele não ter a seniority caracterizada parece ter pesado contrariamente em termos de benefícios dessa condição para a carreira política. Como em qualquer outra colocação profissional, existem titulares da agenda mais ou menos experientes.

Todos os parlamentares estudados, à exceção de Renato Amary, tinham longa participação no parlamento. Entre aqueles que decidiram concorrer às eleições, apenas o deputado Renato Amary não conseguiu se reeleger. Isso parece confirmar nossa expectativa de que, para ser beneficiado em termos de carreira ao assumir a condição de titular da agenda, o político deve ter tempo para construir redes dentro do Congresso. Com relação aos demais deputados, todos eles mantiveram seus mandatos. Julgamos que ser titular da agenda permitiu que eles tivessem mais acesso aos recursos políticos de seus partidos, o que traz vantagens especialmente àqueles que fazem parte da base de apoio ao governo.

Cabe notar que, para quase todos os casos, havia um foco temático ou um nível de especialização desenvolvida ao longo das legislaturas ou de cada experiência pregressa, alçando os atores políticos à condição de titulares da agenda. No entanto, como indicado no exemplo do deputado Henrique Eduardo Alves, a habilidade de articulação política pode predominar sobre a especialização temática. Deve ser percebido que essa habilidade não é decorrência direta do exercício da liderança partidária. A dinâmica do Congresso mostra que nem todo líder de partido atua como titular da agenda.

\section{Considerações finais}

Considera-se que os estudos sobre carreiras políticas devem ser complementados e aperfeiçoados com análises que retratem de forma mais detalhada a complexidade do processo da produção de leis. O trabalho legislativo em senso estrito tem sido subdimensionado nas pesquisas nesse campo. Sabe-se que o Executivo é ator poderoso em nosso presidencialismo de coalizão, mas a atuação dos parlamentares na elaboração de leis, por iniciativa própria ou mediante alterações nas propostas do presidente da República, não pode ser desconsiderada. Note-se que não se está assumindo uma posição simplista de que a tarefa de legislar deve caber apenas ao legislador. A defesa explícita que se faz é da necessidade de estudos mais detalhados sobre a dinâmica interna do parlamento e suas implicações. 
Para análises mais aprofundadas da arena de produção de leis e sua relevância na construção de carreiras políticas, faz-se necessário aplicar estudos de caso. Reconhecemos que há dificuldades nesse âmbito associadas ao método de seleção dos casos, bem como limitações em termos de obtenção de conclusões mais gerais. Não obstante, acreditamos que a intensificação da aplicação desse tipo de estudo poderá reunir um conjunto de informações suficiente para que se obtenham conclusões consistentes sobre o tema, incluindo diferenciação de padrões em termos de atuação política e carreiras.

Cabe perceber que a decisão por parte do parlamentar de investir na consolidação da qualificação de titular da agenda não implica que os outros caminhos de fortalecimento da carreira, como execução de emendas orçamentárias e assunção de titularidade de cargos públicos, devam ser afastados. $\mathrm{Na}$ verdade, são estratégias diferentes, válidas, e que podem ser trabalhadas paralelamente pelos parlamentares. Mas cada uma delas implica níveis de atuação específicos e com graus de dificuldade diferentes.

Esses achados são fruto de esforço ainda exploratório que necessitam ser complementados e testados por pesquisas que reúnam outros casos e agreguem mais elementos ao estudo aqui apresentado. Nesse sentido, ressaltamos a pesquisa de Silva e Araújo (2012), que empreende um esforço metodológico para mapear e rastrear casos concretos de atuação de titulares da agenda. Os autores empregaram três abordagens nesse sentido: a apropriação da agenda do Legislativo, o processo legislativo realizado por meio das comissões especiais na Câmara dos Deputados e a participação dos relatores na tramitação das medidas provisórias. Os resultados parecem promissores e reforçam a tese central deste artigo: a de que há uma relação forte entre o status de titular da agenda e o fortalecimento das carreiras políticas. Por um lado, ser titular da agenda é fator que agrega capital político e fortalece carreiras. Por outro, quanto mais consolidada é a carreira política, maiores possibilidades tem o ator de assumir a condição de titular da agenda.

\section{Referências}

AMORIM NETO, Octavio (2006). Presidencialismo e governabilidade nas Américas. Rio de Janeiro: Editora FGV.

AMORIM NETO, Octavio \& SANTOS, Fabiano (2003). "O segredo ineficiente revisto: o que propõem e o que aprovam os deputados brasileiros". Dados, v. 46, n. 4, p. 661-698. 
ARAÚJO, Suely M. V. G. \& SILVA, Rafael S. (2011). "Reflexões sobre os estudos legislativos no Brasil: por um retrato mais fidedigno do parlamento e dos parlamentares". Trabalho apresentado no I Encuentro Internacional Legislativos en América Latina. Belo Horizonte, 19 a 21 de outubro. FIGUEIREDO, Argelina \& LIMONGI, Fernando (2001). Executivo e Legislativo na nova ordem constitucional. 2. ed. Rio de Janeiro: Editora FGV. LEONI, Eduardo; PEREIRA, Carlos \& RENNÓ, Lúcio (2003). "Estratégias para sobreviver politicamente: escolhas de carreiras na Câmara de Deputados do Brasil". Opinião Pública, v. 9, n. 1, p. 44-67.

MAYHEW, David (1974). Congress: the electoral connection. New Haven: Yale University Press.

MIGUEL, Luis Felipe (2003). "Capital político e carreira eleitoral: algumas variáveis na eleição para o Congresso brasileiro". Revista de Sociologia e Política, n. 20, p. 115-133.

OLIVEIRA, Mariana S. C. (2005). "Participação, saúde e direito na Assembléia Nacional Constituinte: um resgate do debate”. Trabalho apresentado no XIV Congresso Nacional do Conselho Nacional de Pesquisa e Pós-Graduação em Direito. Fortaleza, 3 a 5 de novembro. PEREIRA, Carlos; POWER, Timothy \& RENNÓ, Lúcio (2005). “Under what conditions do presidents resort to decree power? Theory and evidence from the Brazilian case”. Journal of Politics, v. 67, n. 1, p. 178-200.

PEREIRA, Carlos \& RENNÓ, Lúcio (2001). “O que é que o reeleito tem? Dinâmicas político-institucionais locais e nacionais nas eleições de 1998 para a Câmara dos Deputados”. Dados, v. 44, n. 2, p. 323-362.

(2007). "O que é que o reeleito tem? O retorno: o esboço de uma teoria da reeleição no Brasil”. Revista de Economia Política, v. 27, n. 4, p. 664-682.

ROHDE, David W. (1979). "Risk-bearing and progressive ambition: the case of members of the United States House of Representatives". American Journal of Political Science, v. 23, n. 1, p. 1-26.

SABATIER, Paul A. \& JENKINS-SMITH, Hank C. (eds.) (1993). Policy change and learning: an advocacy coalition approach. Boulder: Westview. (1999). "The advocacy coalition framework: an assessment", em SABATIER, Paul A. (ed.). Theories of the policy process. Boulder: Westview.

SAMUELS, David (2000). "Ambition and competition: explaining 
legislative turnover in Brazil”. Legislative Studies Quarterly, v. 25, n. 3, p. 481-497.

SANTOS, Fabiano (1997). "Patronagem e poder de agenda na política brasileira". Dados, v. 40, n. 3, p. 465-492.

SANTOS, Fabiano \& ALMEIDA, Acir (2005). “Teoria informacional e a seleção de relatores na Câmara dos Deputados”. Dados, v. 48, n. 4, p. 693-735.

SENA, Paulo (2008). "A legislação do Fundeb”. Cadernos de Pesquisa, v. 38, n. 134, p. 319-340.

SCHLESINGER, Joseph (1966). Ambition and politics: political careers in the United States. Chicago: Rand McNally.

SILVA, Rafael S. \& ARAÚJO, Suely M. V. G (2010a). "Apropiación de la agenda legislativa: usurpación o cooperación entre los poderes?”. Trabalho apresentado no V Congreso Latinoamericano de Ciencia Política. Buenos Aires, 28 a 30 de julho.

(2010b). "Apropriação da agenda do legislativo: como aferir esse fenômeno?". Texto para Discussão. Centro de Estudos da Consultoria, Senado Federal, v. 76.

(2012). "Os agenda holders no Congresso Nacional Brasileiro". Trabalho apresentado no VI Congreso Latinoamericano de Ciencia Política. Quito, 12 a 14 de junho.

\section{Resumo}

Este trabalho estuda a atuação dos titulares da agenda, conceito que abrange os parlamentares que, em temas determinados, centralizam articulações políticas entre os demais parlamentares, o Poder Executivo e representantes do empresariado e da sociedade civil organizada. Por meio de estudos de processos legislativos, complementados com informações sobre a carreira política de parlamentares, o propósito é indicar caminhos para que se compreenda quem são os titulares da agenda, como eles atuam e qual a conexão com suas carreiras políticas. Os resultados apontam para a existência de vínculo relevante entre carreiras e a atuação de parlamentares como articuladores de atores governamentais e não governamentais.

Palavras-chave: carreira parlamentar; titulares da agenda; apropriação da agenda; capital político; processo legislativo.

\section{Abstract}

This work studies the performance of the agenda holders, a concept that covers the parliamentarians that in certain themes, centralize political articulations among other 
lawmakers, the Executive and representatives from business and civil society organizations. Through studies of legislative processes, supplemented with details on the political career of parliamentarians, the purpose is to indicate ways in order to understand who are the agenda holders, how they act, and the connection with their political careers. The results indicate the existence of a significant relationship between careers and the role of parliamentarians as articulators of governmental and nongovernmental organizations. Key words: parliamentary career; agenda holder; agenda appropriation; political capital; legislative process.

Recebido em 31 de janeiro de 2012.

Aprovado em 2 de julho de 2012. 